\title{
AÇõES E REFLEX̃̃eS dOS DOCENTES NO DESENVOLVIMENTO DA PRÁtICA PEDAgógica na eduCAČ̃̃ PROFISSIONAL E TECNOLÓgICA
}

TEACHERS' ACTIONS AND REFLECTIONS IN DEVELOPMENT OF EDUCATIONAL PRACTICE IN THE PROFESSIONAL AND TECHNOLOGICAL EDUCATION

ACCIONES Y REFLEXIONES DE LOS DOCENTES EN EL DESARROLLO DE LA PRÁCTICA PEDAGÓGICA EN LA EDUCACIÓN PROFESIONAL Y TECNOLÓGICA

\begin{abstract}
RESUMO: Com a criação dos Institutos Federais (IF) ao final do ano de 2008 (Lei 11.892/08), novas configurações se apresentam para o ensino nessas instituições e, em consequência, novas demandas para a formação e o trabalho dos docentes. Nesse contexto, esse trabalho tem como objetivo identificar e analisar as ações e reflexões dos professores de cursos de educação profissional técnica de nível médio, no desenvolvimento de sua prática pedagógica. São apresentados resultados parciais de uma tese de doutorado que investiga a docência da Educação Profissional e Tecnológica no contexto de um Instituto Federal de Educação, Ciência e Tecnologia. A pesquisa caracterizou-se como um estudo de caso, utilizando, questionários, análise documental, observações da prática docente e entrevistas com os professores. As análises são baseadas nos estudos de Chevallard e Shulman, entre outros. Os resultados apontam que os professores dos cursos técnicos utilizam diferentes estratégias de didatização no ensino nas disciplinas técnicas, com ênfase na relação teoriaprática. $\mathrm{O}$ estudo possibilita reflexões sobre as singularidades da prática pedagógica na educação profissional e tecnológica.
\end{abstract}

PALAVRAS-CHAVE: Educação profissional e tecnológica. Prática pedagógica. Didatização

\begin{abstract}
With the creation of the Federal Institutes (IF) at the end of 2008 (Law 11,892 / 08), new configurations are presented for teaching in these institutions and, consequently, new demands for the formation and work of teachers. In this context, this work aims to identify and analyze the actions and reflections of the teachers of technical vocational courses at the intermediate level in the development of their pedagogical practice. Partial results are presented of a doctoral thesis that investigates the teaching of Professional and Technological Education in the context of a Federal Institute of Education, Science and Technology. The research was characterized as a case study, using, questionnaires, documentary analysis, observations of the teaching practice and interviews with the teachers. The analyzes are based on the studies of Chevallard and Shulman, among others. The results show that the teachers of the technical courses use different strategies of teaching in the technical subjects, with emphasis on the theory-practice relationship. The study allows reflections on the singularities of pedagogical practice in professional and technological education.
\end{abstract}

KEYWORDS: Professional and technological education. Teaching practice. Didactization.

RESUMÉN: Con la creación de los Institutos Federales (IF) al final del año 2008 (Ley 11.892 / 08), nuevas configuraciones se presentan para la enseñanza en esas instituciones y, en consecuencia, nuevas demandas para la formación y el trabajo de los docentes. En este contexto, este trabajo tiene como objetivo identificar y analizar las acciones y reflexiones de los profesores de cursos de educación profesional técnica de nivel medio, en el desarrollo de su práctica pedagógica. Se presentan resultados parciales de una tesis de doctorado que investiga la docencia de la Educación Profesional y Tecnológica en el contexto de un Instituto Federal de Educación, Ciencia y Tecnología. La investigación se caracterizó como un estudio de caso, utilizando, cuestionarios,

Submetido em: 16/09/2016 - Aceito em: 08/05/2017 - Publicado em: 23/10/2017.

\begin{tabular}{l|l|l|l|l|l|l} 
(C) Rev. Educ. Perspec. & Viçosa, $M G$ & v.8 & n.2 & p.250-266 & maio/ago. 2017 & eISSN 2178-8359 \\
\hline
\end{tabular}


análisis documental, observaciones de la práctica docente y entrevistas con los profesores. Los análisis se basan en los estudios de Chevallard y Shulman, entre otros. Los resultados apuntan que los profesores de los cursos técnicos utilizan diferentes estrategias de didatización en la enseñanza en las disciplinas técnicas, con énfasis en la relación teoría-práctica. El estudio posibilita reflexiones sobre las singularidades de la práctica pedagógica en la educación profesional y tecnológica.

PALABRAS ClAVE: Educación profesional y tecnológica. Práctica pedagógica. Didatización.

\section{INTRODUÇÃO}

A docência na Educação Profissional e Tecnológica vem sendo objeto de alguns estudos na última década, ainda que seja uma temática pouco investigada no âmbito das pesquisas sobre a formação docente em geral. A criação dos Institutos Federais (IF) no contexto da expansão da Rede Federal de Educação Profissional, Científica e Tecnológica (Lei 11.892/08) apresenta novas configurações para o ensino nessas instituições e, em consequência, novas demandas para a formação dos docentes que aí atuam. Tais institutos são instituições de educação superior, básica e profissional, pluricurriculares e multicampi, especializadas na oferta de formação inicial e continuada ou de qualificação profissional; de Educação Profissional técnica de nível médio; de Educação Profissional tecnológica de graduação e pós-graduação, tendo como base a conjugação de conhecimentos técnicos e tecnológicos com as suas práticas pedagógicas, devendo atuar no ensino, na pesquisa e na extensão.

Um dos aspectos que se apresentam na organização do ensino nos Institutos Federais é a diversificação de cursos ofertados: cursos técnicos integrados, subsequentes ou concomitantes ao ensino médio, bem como os cursos superiores de Licenciatura, Bacharelado e Tecnólogos e ainda, cursos de pós-graduação. Sendo assim, o trabalho pedagógico dos professores dos Institutos Federais desenvolve-se em um contexto em que diferentes níveis e modalidades de ensino são ofertados, o que traz em seu bojo a heterogeneidade do perfil dos alunos que frequenta cada tipo de curso, que por sua vez apresentam diferentes demandas de trabalho ao professor: no ensino técnico integrado ao médio, o público-alvo são alunos recém-saídos do ensino fundamental, ainda na fase da adolescência; no ensino técnico concomitante ou subsequente ao ensino médio, o professor trabalha com um alunado heterogêneo que está cursando ou já concluiu o ensino médio, e em muitos casos, já está inserido no mundo do trabalho. Acrescente-se a essa diversidade, os cursos técnicos na modalidade a distância. Além disso, as matrizes curriculares distintas acarretam grande diversidade na organização do trabalho pedagógico, demandando do professor atenção constante em seu cotidiano de trabalho.

Nesse trabalho, o foco são os cursos técnicos de nível médio, pois se busca analisar a prática pedagógica nas disciplinas técnicas ${ }^{2}$, aquelas que tratam da formação específica dos alunos

\begin{tabular}{l|l|l|l|l|l|l} 
(C) Rev. Educ. Perspec. & Viçosa, $M G$ & v.8 & n.2 & p.250-266 & maio/ago. 2017 & eISSN 2178-8359 \\
\hline
\end{tabular}


visando proporcionar a eles o embasamento teórico-prático do conhecimento necessário para sua atuação profissional futura. Tais disciplinas inserem-se no currículo dos cursos técnicos de duas formas: (1) nos cursos técnicos integrados, as matrizes curriculares são compostas por duas partes: base nacional comum e parte diversificada, que englobam as disciplinas da Área Básica (disciplinas do ensino médio) e pela Parte de Formação Específica (que é composta pelas disciplinas técnicas, que se caracterizam por fornecer os conhecimentos específicos que visam à formação do aluno para o mundo do trabalho). Essas disciplinas variam conforme o perfil do profissional a ser formado em cada curso. As disciplinas da base nacional comum são as mesmas em todos os cursos e são comuns a todos as escolas de ensino médio. A distribuição das disciplinas da área básica e da área técnica é diferenciada no decorrer das séries dos cursos técnicos integrados na Instituição pesquisada, pois o curso se inicia com poucas disciplinas técnicas na $1^{\text {a }}$ série e esse número vai aumentando gradativamente até a $3^{a}$ série. Tal organização curricular, ao mesmo tempo em que confere identidade ao curso, insere gradativamente o aluno na formação pretendida. Para dar conta desta matriz curricular extensa, os cursos técnicos integrados funcionam em regime de tempo integral no turno diurno. (2) Nos cursos técnicos subsequentes ao ensino médio, as matrizes curriculares são organizadas somente com as disciplinas técnicas. Outra particularidade desse tipo de curso é ser ofertado na maioria das vezes no turno noturno.

O ensino de disciplinas técnicas apresenta diferenças no trabalho docente em comparação com as disciplinas das áreas básicas, pois demanda constante atualização em relação às tecnologias, relação com a prática do campo de trabalho para o qual se destina a formação do aluno em cada curso, que pressupõe o conhecimento técnico-prático do conteúdo objeto de ensino, a organização das aulas de laboratório, bem como necessária relação teoria e prática. Esses aspectos demarcam uma singularidade na docência na Educação Profissional e Tecnológica. Os professores dessas disciplinas, no contexto pesquisado, são engenheiros com mestrado e/ou doutorado e não possuem formação para o ensino. Sendo assim, na busca de transformar seu conhecimento do conteúdo específico em um conhecimento ensinável, utilizam diferentes estratégias de didatização para desenvolver sua prática pedagógica.

Tendo por base estudos de Caldeira e Zaidan (2010), a prática pedagógica está sendo entendida como o conjunto dos processos formativos desenvolvidos junto aos alunos, mediados pela ação do professor no cotidiano do trabalho docente, o que, no caso dos cursos técnicos, não ocorre somente nas salas de aula, mas também em laboratórios, visitas técnicas, feiras, entre outros espaços.

\begin{tabular}{l|l|l|l|l|l|l} 
(C) Rev. Educ. Perspec. & Viçosa, $M G$ & v.8 & n.2 & p.250-266 & maio/ago. 2017 & eISSN 2178-8359 \\
\hline
\end{tabular}




\section{APORTES TEÓRICOS: TRANSPOSIÇÃO DIDÁTICA E CONHECIMENTO PEDAGÓGICO DO CONTEÚDO}

Para Chevallard (1991) a transposição didática refere-se ao trabalho que transforma um objeto de saber em um objeto de ensino, ou seja, relaciona-se às transformações que um saber sofre quando passa de um campo científico para o campo escolar, tornando-se diferente do saber acadêmico, porque para ser ensinado o saber precisa ser simplificado, ensinado num tempo pré-estabelecido e avaliado na escola. Chevallard (1991) afirma que o professor busca transpor o conhecimento a ser ensinado para um conhecimento adequado para o ensino, recriando-o em uma lógica de aprendizagem, fazendo uso de formas de simplificação dos conteúdos, organizando-os para ensiná-los de forma a facilitar a compreensão para que possam ser aprendidos pelos alunos. Para isso, utiliza-se de diferentes estratégias de didatização, tais como exemplificação, ilustrações, graduação de dificuldades, sequência, adequação ao nível de ensino, exercícios e questões, organizando o conhecimento em um programa escolar para que possa ser ensinado e avaliado.

O trabalho de transposição didática, para Forquin (1992), ocorre na educação escolar quando é feita uma seleção entre os saberes e materiais culturais disponíveis numa dada sociedade, realizando-se um grande trabalho de reorganização para tornar tais saberes passíveis de transmissão para as novas gerações, sendo necessária a utilização de "dispositivos mediadores" que possibilitem o ensino. Nesse sentido, a cultura escolar apresenta-se como uma segunda cultura em relação à cultura de invenção ou criação, subordinada a uma função de mediação didática, de didatização, manifestada em programas, instruções oficiais, materiais didáticos, notas, classificações, dentre outros aspectos, que geram traços característicos dos saberes escolares.

A investigação sobre as relações entre o conhecimento do conteúdo e a prática docente, sobre o processo de transformação do conhecimento específico para o processo de ensino, pode ser baseada também nos aportes dos estudos de Shulman $(2005 \mathrm{a} ; 2005 \mathrm{~b})^{3}$. Para o autor, existe uma base de conhecimentos para o ensino se refere a um repertório profissional que contém categorias de conhecimento que subjazem à compreensão que o professor necessita para promover as aprendizagens dos alunos e se configura com os seguintes tipos de conhecimentos: conhecimento do conteúdo; conhecimento pedagógico geral; conhecimento do currículo; conhecimento pedagógico do conteúdo; conhecimento dos alunos e de suas características; conhecimento dos contextos educativos; conhecimento dos objetivos, das finalidades e dos valores educacionais e de seus fundamentos filosóficos e históricos (SHULMAN, 2005b, p. 11, tradução nossa). Para esse trabalho, será utilizado o conceito do conhecimento pedagógico do conteúdo (CPC), tal como proposto por Shulman (2005a). Para o autor, esse tipo de conhecimento insere-se na base de conhecimentos necessários para o

\begin{tabular}{l|l|l|l|l|l|l}
\hline (c) Rev. Educ. Perspec. & Viçosa, $M G$ & v.8 & n.2 & p.250-266 & maio/ago. 2017 & eISSN 2178-8359 \\
\hline
\end{tabular}


ensino e refere-se àquele que vai além do conhecimento da matéria propriamente dita, pois engloba o conhecimento da matéria para ensiná-la (SHULMAN, 2005a, p. 212, grifos do autor). Dentro do CPC, o autor inclui:

[...] as formas mais úteis de expor as ideias, as melhores analogias, descrições, exemplos, explicações e demonstrações, ou seja, as formas de apresentar e expor uma matéria para que os outros compreendam. Como não existem formas únicas de expor que sejam melhores, o professor deve administrar um verdadeiro arsenal de formas alternativas, algumas embasadas em pesquisas e outras na experiência prática (tradução nossa).

O CPC inclui também a compreensão daquilo que facilita ou dificulta a aprendizagem dos alunos de diferentes idades e contextos de ensino e é o tipo de conhecimento que fornece ao professor as estratégias para ensinar um conteúdo específico, as formas de organizá-lo para que os alunos compreendam. É o conhecimento que, articulado com o conhecimento do conteúdo a ensinar, confere ao professor a capacidade de transformar seu conhecimento da matéria em formas que sejam didaticamente adequadas para ensinar, atendendo a diversidade de habilidades e conhecimentos prévios dos alunos. Pode-se dizer então que o CPC compreende as formas de apresentar a matéria para torná-la compreensível para os alunos.

Desse modo, para tornar um conhecimento ensinável, o professor utiliza-se de diferentes estratégias de didatização no processo de transposição didática. Essas estratégias requerem do professor não apenas os conhecimentos de sua área específica, é necessário que os conhecimentos do conteúdo sejam reorganizados em uma perspectiva pedagógica, o que implica em planejamento, seleção e organização dos conteúdos em uma sequência adequada, considerando o nível de ensino, o perfil dos alunos, o tempo de aprendizagem, o contexto institucional, entre outros aspectos. Pressupõe ainda a seleção de materiais didáticos, a articulação com as novas tecnologias e a busca de estratégias adequadas de ensino visando relacionar o conteúdo com sua aplicabilidade em situações reais, possibilitando uma aprendizagem significativa e contextualizada.

\section{PERCURSO METODOLÓGICO DO ESTUDO}

A investigação que serve de base para esse trabalho é uma tese de doutorado, como dito anteriormente, e os sujeitos da pesquisa são professores do Instituto Federal Minas Gerais, com tempos variados de experiência na docência. Foi realizada uma pesquisa de abordagem qualitativa (ANDRÉ, 2008; BOGDAN, BIKLEN, 1994; POUPART, et al., 2010) e como estratégia metodológica, foi realizado um estudo de caso, que se utilizou de questionários e análise documental e posteriormente de entrevistas e observação da prática docente.

\begin{tabular}{l|l|l|l|l|l|l} 
(C) Rev. Educ. Perspec. & Viçosa, $M G$ & v.8 & n.2 & p.250-266 & maio/ago. 2017 & eISSN 2178-8359 \\
\hline
\end{tabular}


Para esse trabalho está sendo feito um recorte, de modo a abordar os dados obtidos nas observações e entrevistas. Essas foram realizadas com seis professores, todos com formação em Engenharia, sendo que dois professores possuem o título de Doutor e quatro, de Mestre. Desses, um estava cursando doutorado no momento de realização da pesquisa. Nenhum deles possui formação voltada para o ensino. Cinco realizaram o Curso Técnico de Nível Médio na mesma área em que atuam como professores, sendo quatro são ex-alunos da Instituição, na qual atuam como professores.

Serão examinados, no âmbito desse artigo, apenas dados referentes às práticas pedagógicas de dois professores, sendo um do Curso Técnico em Edificações e outro do Curso Técnico em Automação Industrial, ambos integrados ao ensino médio. As observações foram realizadas durante um bimestre na sala de aula de cada professor e as entrevistas foram realizadas após o término do conjunto das observações. São apresentadas as formas de desenvolvimento da prática docente e as percepções dos docentes sobre sua prática, centrando as análises nas estratégias de didatização utilizadas para transformar o conteúdo para o ensino, tornando-o compreensível para o aluno e propiciando a aprendizagem.

É importante explicitar que as análises das práticas pedagógicas aqui apresentadas não têm a intenção de julgamento do trabalho realizado pelos professores. O que se pretende é uma aproximação com o contexto real da docência na EPT, buscando refletir sobre o seu processo de constituição e desenvolvimento no cotidiano da sala de aula dos professores na Instituição.

O professor Leonardo ${ }^{4}$ é graduado em Engenharia Civil e em Direito, com Mestrado em Engenharia Civil e no momento da pesquisa estava cursando o doutorado na mesma área. Tem 44 anos e 19 anos de experiência no magistério na instituição pesquisada. O Professor Vinícius é graduado em Engenharia Elétrica e Doutor em Engenharia Agrícola. Tem 40 anos e 14 anos de experiência docente na instituição. Ambos são ex-alunos de cursos técnicos da instituição.

\section{O ENSINO DAS DISCIPLINAS TÉCNICAS: AS AÇÕES E AS REFLEXÕES DOS PROFESSORES}

Nessa seção são apresentados os dados obtidos nas observações das aulas e nas entrevistas com os professores, de forma a evidenciar as formas de desenvolvimento da prática. Busca-se analisar a ação pedagógica dos professores e suas reflexões sobre essas ações no contexto dos cursos técnicos.

\begin{tabular}{l|l|l|l|l|l|l} 
(C) Rev. Educ. Perspec. & Viçosa, $M G$ & v.8 & n.2 & p.250-266 & maio/ago. 2017 & eISSN 2178-8359 \\
\hline
\end{tabular}


A observação da prática docente, do "terreno da docência" (TEIXEIRA, 2007) foi uma das formas de investigação utilizada para acessar a prática pedagógica dos professores sujeitos dessa pesquisa. A partir da observação, que durou um bimestre letivo na sala de aula de cada professor, foram realizadas entrevistas, por meio das quais foi possível identificar as percepções desses professores sobre a própria prática e as explicações sobre as estratégias de didatização utilizadas nas situações de ensino, bem como sobre as especificidades das disciplinas técnicas.

As aulas ministradas pelo professor Leonardo foram desenvolvidas em uma turma de $2^{\mathrm{a}}$ série do Curso Técnico Integrado em Edificações, composta por 24 alunos, sendo 14 mulheres, na faixa etária de 15 e 16 anos, do turno da manhã. O professor iniciava as aulas fazendo anotações de um roteiro no canto do quadro sobre os temas que seriam estudados no dia. Antes de iniciar o conteúdo propriamente dito, ele fazia uma explanação sobre tais tópicos, introduzindo o assunto. Era organizado e distribuía adequadamente o tempo da aula, concluindo os assuntos planejados. Usava tom de voz baixo e firme, sendo objetivo em suas explicações e ao mesmo tempo atento aos comentários e dúvidas dos alunos durante as aulas.

Pôde-se constatar, no período observado, que o professor Leonardo buscou fazer a transformação do conteúdo para ensiná-lo, ou seja, procurou didatizar os conteúdos utilizando-se de diferentes estratégias no processo de transposição didática, como apontando por Forquin (1992). Segundo o professor, a exemplificação e a ilustração eram necessárias para o entendimento do conteúdo pelos alunos, pois o assunto dessa disciplina é, no dizer do professor "muito árido", por isso ele utiliza estratégias diversificadas para ensinar: "Eu uso muita exemplificação, muita ilustração, uso muitas transparências... [...] Eu procuro sempre referenciar no dia a dia com os exemplos, para ajudar".

Foi constante nas aulas a ilustração da matéria com situações reais fazendo referências ao cotidiano dos alunos para que eles entendessem a aplicabilidade dos temas estudados. De acordo com o professor, não é fácil para um aluno adolescente aprender essa disciplina, por isso ele busca contextualizar o ensino citando fatos ou situações presentes na realidade dos alunos. Ele afirmou que usa exemplos da região, como obras no centro de convenções, onde é feito o carnaval, que os alunos gostam muito. Mostra também exemplos de obras em campo de futebol, contextualizando com as reformas dos campos para a Copa do Mundo que estava ocorrendo no momento, mostrando, por exemplo, como é feita uma obra no solo, debaixo dos campos de futebol para drenar a água da chuva. Em sua opinião, essas técnicas de aproximação dos conteúdos com o universo do estudante são muito importantes. A utilização dessas formas de ensino mostra a consideração do professor pelo perfil da turma:

Às vezes é difícil uma pessoa de 15, 16 anos, começar a tratar de "fundação de edifícios", são vários termos técnicos que a pessoa não conhece e a gente precisa ter

\begin{tabular}{l|l|l|l|l|l|l} 
(C) Rev. Educ. Perspec. & Viçosa, $M G$ & v.8 & n.2 & p.250-266 & maio/ago. 2017 & eISSN 2178-8359 \\
\hline
\end{tabular}


muito cuidado no uso do termo técnico. Eu tento falar de uma forma clara o que é "bulbo de pressões", por exemplo. É um assunto que eu ensinei agora na semana passada. Então você tem que usar de uma estratégia pro aluno aprender. É difícil pra uma pessoa de 15 anos, eles não estão falando disso. Eles estão falando de uma banda de rock, de axé, de Facebook, do namorado, da namorada... outro universo. E se você falar só o termo técnico eles não vão entender o que é. Então tem que ter todo esse jeito.

A dificuldade da disciplina, relatada pelo professor, é um dos aspectos que o leva a buscar diferentes estratégias para trabalhar de modo que os alunos possam compreender o conteúdo. Ele afirma que, por ser uma disciplina de segunda série do curso de Edificações, em que ocorre o primeiro contato dos alunos com as disciplinas técnicas ${ }^{5}$, essa acaba trazendo dificuldades de diferentes ordens para a aprendizagem:

\begin{abstract}
Mecânica dos solos é uma disciplina difícil, é uma disciplina que dá trabalho. E como você viu, tem uma vertente de laboratório. Além da sala de aula, da teoria e de exercícios com os cálculos, ainda tem as questões laboratoriais. Então é uma disciplina rica nesse contexto, mas que por sua vez também exige boa uma formação em matemática, física... É muito cálculo. E no laboratório exige uma certa habilidade no manuseio daqueles equipamentos. Então, eu procuro trazer pro nível médio, de um estudante de ensino técnico, pra ela ficar assim, vamos dizer, mais... leve.
\end{abstract}

Essa percepção do professor, decorrente de seu conhecimento profundo da disciplina, demonstra sua preocupação em transformar o conteúdo para ensiná-lo, utilizando as estratégias descritas acima, destacando sua utilização do conhecimento pedagógico do conteúdo. As ações deste professor podem ser analisadas tomando-se como base as ideias de Shulman (2005b), que mostra que frente à diversidade de seus alunos, o docente deve ter uma compreensão flexível e multifacetada, que lhe possibilite planejar explicações alternativas dos mesmos conceitos ou princípios, tendo por base o conhecimento das estruturas da matéria. De acordo com esse autor especificidade do professor reside na capacidade de transformar os conhecimentos que domina em conhecimentos assimiláveis pelos alunos mediante o processo de ensino, valorizando, assim, a compreensão profunda dos conteúdos como um momento prévio ao ensino.

A relação teoria e prática é trabalhada em suas aulas, utilizando-se das estratégias de ilustrações, exemplificações e contextualização, que são constantes em seu dia a dia, tais como observado nos registros das aulas. Quanto às aulas práticas, Leonardo explica que elas exigem dele uma postura diferente, tanto no planejamento quanto durante a aula propriamente dita, porque "os alunos ficam muito dispersos ali e não tem aquela postura convencional de ficar sentado em frente a um quadro negro. São aulas que exigem empenho deles para fazer as atividades". De acordo com o professor, devido à natureza da disciplina, os exercícios são necessários para efetuar os cálculos para dimensionar os processos em estudo.

\begin{tabular}{l|l|l|l|l|l|l} 
(C) Rev. Educ. Perspec. & Viçosa, $M G$ & v.8 & n.2 & p.250-266 & maio/ago. 2017 & eISSN 2178-8359 \\
\hline
\end{tabular}


Durante algumas das aulas observou-se que uma parte do tempo era destinada à resolução de exercícios, quando o professor questionava os alunos, apresentava desafios e simulações de situações de aplicação dos cálculos feitos, chamando a atenção para aspectos importantes e para a utilização correta das fórmulas e unidades de medida. Nesses exercícios estavam presentes diversos cálculos que exigiam conhecimentos de física e de matemática, que segundo o professor, exercem papel importante no contexto dessa disciplina técnica. $\mathrm{O}$ uso de questionamentos durante as aulas foi constante, pois em todas as explicações, o professor buscava envolver os estudantes no assunto para participarem das aulas, darem exemplos, fazerem comentários. As questões feitas pelo professor contribuíam para melhor compreensão dos conteúdos ensinados. Leonardo se pautou nas especificidades da disciplina e no perfil da turma para organizar as aulas buscando aproximar os temas da realidade dos alunos adolescentes da $2^{a}$ série do curso de Edificações. Trata-se de uma disciplina com temas teóricos que precisaram de explicações detalhadas, ilustrações e uma gama de exemplos contextualizados com situações reais da cidade e região, bem como de aulas práticas que contribuíssem para tornar acessível o conteúdo ensinado em aulas expositivas muito bem organizadas pelo professor.

É por meio dessas estratégias de didatização que o professor realiza a transformação de seu conhecimento do conteúdo em formas adequadas para a aprendizagem dos alunos, buscando ultrapassar o conhecimento da matéria propriamente dita, adequando-a ao processo de ensino, como afirma Shulman (2005a). Para o autor, o conhecimento pedagógico do conteúdo é aquele que, articulado com o conhecimento do conteúdo a ensinar, confere ao professor a capacidade de transformar seu conhecimento da matéria em formas que sejam didaticamente adequadas para ensinar, atendendo a diversidade de habilidades e conhecimentos prévios dos alunos. Pode-se dizer, então, que esse conhecimento compreende as formas de apresentar a matéria para torná-la compreensível para os alunos, conforme visto na prática do professor Leonardo.

A outra turma observada foi o terceiro ano do Curso Técnico Integrado em Automação Industrial, que conta com 18 alunos $^{6}$ com idade entre 17 e 18 anos. Nessa turma, o Professor Vinícius ministra aulas da disciplina Eletrônica Industrial, que são organizadas em dois horários seguidos de cinquenta minutos e são ministradas uma vez por semana, na parte da manhã. Predominaram nas aulas a orientação e o atendimento aos grupos de alunos enquanto desenvolviam atividades práticas em um laboratório composto por seis bancadas onde estão alocados dezoito computadores e um quadro branco. Ao chegar à sala de aula, os alunos acomodavam-se em frente a cada computador, abrindo os arquivos necessários à aula do dia e ou aguardando orientações do professor. Essa disciplina é trabalhada com os concluintes do curso de Automação Industrial e apresentou uma vertente prática predominante no período

\begin{tabular}{l|l|l|l|l|l|l} 
(C) Rev. Educ. Perspec. & Viçosa, $M G$ & v.8 & n.2 & p.250-266 & maio/ago. 2017 & eISSN 2178-8359 \\
\hline
\end{tabular}


observado. Um aspecto que chamou a atenção foi o grau de autonomia e interesse dos estudantes nessas aulas. Eles chegavam e se acomodavam em frente ao computador para realizar os trabalhos, os grupos que terminavam o trabalho saíam mais cedo ou ficavam auxiliando os colegas, outros grupos chegavam após o início, sem perturbar. O professor conseguia estar atento a toda essa movimentação sem perder a sequência da aula.

Vinícius utilizava uma explicação clara, definindo bem os termos técnicos e disponibilizava os programas e conteúdos para os alunos em meio digital. Solicitava a atenção, propunha situações do campo profissional para os alunos resolverem articulando os conteúdos ensinados com os anteriores e com outras disciplinas, demonstrava acreditar na capacidade dos alunos com palavras de incentivo e encorajamento durante as aulas. Nas aulas observadas, o predomínio das atividades práticas colocava a necessidade constante de explicações sobre os procedimentos a serem adotados na tarefa. Entretanto, dadas as especificidades da disciplina no momento da observação das aulas (o fazer um determinado trabalho prático no computador) e o seu local de realização - o laboratório - tais explicações se davam de forma direcionada aos alunos em grupos. Apenas uma aula foi destinada a explicação geral para todos ao mesmo tempo.

Ficou evidente o uso de situações práticas, a simulação de problemas, a testagem do funcionamento de determinados programas no computador, ou seja, nesse período, as práticas de laboratório foram as predominantes durante as aulas. A ilustração se dava mediante menção do professor a práticas relacionadas ao trabalho do técnico. A exemplificação e a ilustração, também mencionadas pelo professor Leonardo nas análises anteriores, constituemse em procedimentos de didatização relevantes na prática docente nos cursos técnicos, pois, conforme destaca o professor Vinícius, pois em sua entrevista, são recursos que contribuem muito para a aprendizagem dos alunos. Segundo ele, há mais interesse nas aulas quando o aluno vê exemplos de aplicação dos conteúdos trabalhados: "Eu sempre procuro colocar um exemplo prático nas aulas. Além desses exemplos práticos, procuro fazer as montagens dos equipamentos para o aluno ver as coisas funcionando, isso motiva muito".

$\mathrm{Na}$ organização das aulas, o professor procurava estabelecer relação da teoria com situações práticas, contextualizando o ensino com exemplos reais e solicitando aos alunos que pensassem como se fossem técnicos em situação de trabalho nas empresas. A aplicabilidade do conteúdo estudado estava sempre presente, pois à medida que as atividades práticas eram feitas, o professor questionava os estudantes e solicitava que fizessem simulações de situações possíveis de acontecer na prática, buscando estabelecer relações com a teoria. "É importante tentar relacionar o conteúdo com o que o aluno vivencia, com uma coisa mais concreta. Então, uma coisa que ele achava difícil, e de repente ele percebe que não era tão difícil, torna-se prazerosa". De acordo com Chevallard (1991), no processo de transposição didática, ocorre uma transformação do conhecimento a ser ensinado para um conhecimento \begin{tabular}{l|c|c|c|c|c|c}
\hline (c) Rev. Educ. Perspec. & Viçosa, $M G$ & v.8 & n.2 & p.250-266 & maio/ago. 2017 & eISSN 2178-8359 \\
\hline
\end{tabular} 
adequado para o ensino, buscando formas de organização que concorram para facilitar a compreensão dos alunos. Esse processo pôde ser observado na prática dos dois professores, conforme mostram os relatos apresentados.

Como se trata de um curso de formação profissional, além dessas estratégias, o professor Vinícius afirma que nas disciplinas de caráter mais prático, é necessário oferecer ferramentas para que o aluno possa se sair bem em uma situação de emprego, além de ensinar como buscar conhecimentos. É nesse contexto que se inserem as visitas técnicas, como uma forma de viabilizar e reforçar a relação com a prática, mostrando exemplos de atuação dos profissionais. Para ele, visualizar na prática das empresas os conceitos trabalhados em sala de aula contribui para aprendizagem e isso motiva mais para o curso técnico.

Os manuais de equipamentos são bastante utilizados nas aulas do curso de Automação Industrial, pois os alunos devem montar programas de computador e verificar seu funcionamento. A partir dos manuais, o professor elabora os tutoriais, que segundo ele são uma forma e de focar nos aspectos mais relevantes para o ensino da disciplina, adequando-os ao nível de aprendizagem dos alunos. A especificidade dessa disciplina foi perceptível também nos tipos de exercícios que eram realizados durante o período observado, pois não se tratava somente de listas com perguntas ou cálculos. Na maior parte das aulas, eram exercícios práticos para serem feitos no computador, buscando "fazer funcionar" o dispositivo que estavam montando ou a atividade definida pelo professor, na qual os alunos testavam diversos valores ou fórmulas em diferentes procedimentos para obter o funcionamento do equipamento ou programa em questão. Esses exercícios com conteúdo aplicado que mobilizavam a atenção dos alunos durante as aulas e os mantinham interessados no trabalho para ver o resultado final. Nas aulas, os estudantes faziam as leituras e atividades no computador e quando precisavam fazer anotações das explicações do professor, abriam um arquivo e digitavam. Raras vezes usavam caderno. Durante a realização de exercícios, o professor questionava, orientava, solicitava simulações com valores diferentes, colocava situações práticas para os alunos resolverem, instigava-os a pensar continuamente e a buscar soluções para os erros que ocorriam durante as atividades realizadas. O professor explicava cada conteúdo mostrando a aplicabilidade do que estava sendo ensinado em situações reais de trabalho.

A preocupação com a progressão nos conteúdos ensinados e com a sequência das aulas aparece na prática do professor quando ele ressalta a importância do planejamento e da organização do seu trabalho com os alunos. Constata-se em sua fala a atenção com a graduação das dificuldades por meio de atividades que viabilizem a aquisição dos conhecimentos de forma progressiva, partindo dos temas e exercícios menos aprofundados para os mais complexos, entendendo essa estratégia como um dos mecanismos para facilitar a

\begin{tabular}{l|l|l|l|l|l|l|}
\hline (c) Rev. Educ. Perspec. & Viçosa, $M G$ & v.8 & n.2 & p.250-266 & maio/ago. 2017 & eISSN 2178-8359 \\
\hline
\end{tabular}


aprendizagem. Esse aspecto foi percebido também nas aulas observadas. Para este professor, na atividade de ensino é importante contextualizar e simplificar os conteúdos para o nível da turma. A organização dos conteúdos nessas aulas aponta aspectos da transposição didática apresentados por Forquin (1992, p. 3), para quem a necessidade de didatização decorre de certos traços característicos dos saberes escolares, sendo comum no processo de ensino:

a predominância de valores de apresentação e de clarificação, a preocupação da progressividade, a importância atribuída à divisão formal (em capítulos, partes e subpartes), a abundância e redundâncias no fluxo informacional, o recurso dos desenvolvimentos perifrásicos, os comentários explicativos, às glosas e, simultaneamente, às técnicas de condensação (resumos, sínteses, documentários, técnicas mnemônicas) à pesquisa de concretização (ilustração, esquematização, exemplificação), o lugar concedido às questões e aos exercícios, tendo uma função de controle ou de reforço, todo esse conjunto de dispositivos e de marcas pela qual se reconhecem um "produto escolar".

As análises realizadas mostram pontos de convergência e de divergências entre as práticas pedagógicas dos dois professores. Como visto, a disciplina ministrada pelo professor Leonardo é bastante teórica, fato que demandou a busca por formas de aproximação com a realidade dos alunos, tanto no que se refere ao uso de exemplos concretos do seu dia a dia quanto na busca de adequação ao perfil da turma aproximando os temas das aulas à realidade dos alunos adolescentes da $2^{\mathrm{a}}$ série do curso de Edificações.

Na disciplina ministrada pelo professor Vinícius, observou-se uma vertente prática que deu um diferencial na forma de ensinar. Ele trabalhava para que os alunos atingissem o objetivo de elaborar um trabalho final que era desenvolver um Projeto de Automação Industrial. Nesse sentido, todas as aulas foram direcionadas para atividades práticas no computador, explicações com simulações de situações de empresas e orientações para a aquisição de conhecimentos que subsidiaram a elaboração e execução do referido Projeto. A exposição dos conteúdos para a turma toda também foi pouco presente, dado o caráter de orientação aos alunos que era predominante.

A postura dinâmica desse professor no sentido de combinar as orientações individuais e em grupos com exposição de conteúdos quando necessário, mantendo a disciplina, dando autonomia para os alunos ao mesmo tempo em que cobrava responsabilidade e resultado nos trabalhos, foi exemplo de transformação do seu conhecimento do conteúdo em uma perspectiva pedagógica, tal como proposto por Shulman (2005b), aliando bom manejo de turma a uma boa relação professor-aluno que contribuíram para o êxito dos trabalhos. Constatou-se ainda que o caráter mais prático dessa disciplina com a proposta de elaboração de trabalho final pode ter contribuído para manter o interesse e a motivação para o desenvolvimento dos trabalhos, o que nem sempre ocorre quando os professores buscam utilizar estratégias que pressupõem trabalhos autônomos pelos alunos.

\begin{tabular}{l|l|l|l|l|l|l} 
(C) Rev. Educ. Perspec. & Viçosa, $M G$ & v.8 & n.2 & p.250-266 & maio/ago. 2017 & eISSN 2178-8359 \\
\hline
\end{tabular}


Portanto, pôde-se constatar que, na prática do professor Leonardo, a ênfase foi em procedimentos didáticos que instrumentalizassem os alunos para o entendimento dos conteúdos, fornecendo embasamento teórico necessário à sistematização e organização do conhecimento, necessário para compreensão das disciplinas posteriores do curso, que exigem processos cognitivos mais complexos e são mais direcionadas à aplicação dos conhecimentos no trabalho do técnico. Já na prática do professor Vinícius, a ênfase foi na aplicabilidade prática dos conhecimentos em projetos e em situações contextualizadas da vida profissional futura dos estudantes, visto que a disciplina ministrada por ele encontrava-se na fase de finalização do curso. Nessas aulas, observou-se que o professor caminhava no sentido de promover a consolidação dos conhecimentos práticos e teóricos adquiridos durante o curso. Em cada disciplina, ficou evidenciado o estilo de ensino singular de cada professor.

As análises realizadas mostram que, no que se refere à forma de organização das aulas, constatou-se no período observado que as estratégias de didatização utilizadas ocorreram, em sua maioria, no contexto de aulas expositivas dialogadas, nas quais se observou constante questionamento dos professores aos alunos e a participação espontânea deles, em interação com o professor. Diferentes estudos têm discutido a pertinência de variadas formas de ensinar, apontando o fato de que a aula expositiva vem sendo criticada por sua associação aos métodos tradicionais. Entretanto, autores como Libâneo (2001), por exemplo, argumentam que a exposição lógica dos conteúdos é necessária e pode ser combinada com outros procedimentos. Para Lopes (2001), a aula expositiva, quando assume a dimensão dialógica, opõe-se à aula expositiva tradicional, visto que o diálogo estimula os alunos a participar da reelaboração dos conhecimentos e os incentiva a produzir novos conhecimentos a partir dos conteúdos aprendidos, pois proporciona a aquisição e análise crítica dos mesmos, "elimina a relação pedagógica autoritária, valoriza a experiência e os conhecimentos prévios dos alunos; estimula o pensamento crítico por meio de questionamentos e problematizações" (LOPES, 2001, p. 45). Durante as aulas observadas, o que se constatou foi a opção dos professores pela aula expositiva dialogada, tal como proposta pela autora, pois a interação foi constante e o diálogo entre professor e alunos permeou as aulas.

A análise da prática docente dos dois professores por meio das observações em suas aulas e de seus depoimentos sobre sua forma de ensinar permite constatar aspectos singulares e convergências, bem como a complexidade da ação pedagógica decorrente da dinâmica instalada no momento em que o professor está desenvolvendo seu trabalho com os alunos. Tal complexidade, ressaltada por diferentes autores, como Perrenoud (1993), Tardif (2008), Santos (2010), entre outros, pode ser constatada nas aulas observadas, visto que os professores desempenhavam diferentes tarefas concomitantemente, como mostra Santos (2010, p. 9):

\begin{tabular}{l|l|l|l|l|l|l} 
(C) Rev. Educ. Perspec. & Viçosa, $M G$ & v.8 & n.2 & p.250-266 & maio/ago. 2017 & eISSN 2178-8359 \\
\hline
\end{tabular}




\begin{abstract}
A prática do professor é complexa, não apenas por envolver diversas habilidades, como também por exigir que muitas delas sejam utilizadas simultaneamente. O professor ao lecionar um determinado conteúdo não tem apenas que dominar o conhecimento daquele campo, como também saber ensiná-lo, subdividindo-o em tópicos, apresentando exemplos, fazendo analogias, criando atividades etc.
\end{abstract}

Percebeu-se empenho dos professores em utilizar estratégias de didatização diversificadas para que os alunos adquirissem/construíssem os conhecimentos necessários para o alcance dos objetivos da disciplina e, em âmbito maior, para a sua formação como profissionais de nível técnico, pois a partir de sua compreensão dos conhecimentos específicos de sua área, tais docentes os transformaram em uma perspectiva pedagógica para viabilizar o ensino.

\title{
CONSIDERAÇÕES FINAIS
}

O trabalho evidenciou que as práticas pedagógicas no ensino técnico pautam-se por diferentes estratégias de didatização e pela ênfase dos professores na relação teoria-prática, tanto na busca de orientar o ensino para possibilitar conhecimentos básicos necessários ao aprofundamento dos estudos em disciplinas posteriores, quanto na busca de demonstrar a aplicabilidade do conhecimento em atividades da futura atuação profissional dos alunos, em um processo dialógico e de construção da autonomia dos alunos. Constatou-se que o conhecimento pedagógico do conteúdo manifestou-se nas práticas docentes analisadas por meio de diferentes estratégias de didatização. Pode-se dizer que o conhecimento do conteúdo é o que se impôs como básico para a organização das aulas, sendo que este foi reelaborado/reorganizado pelos professores de diferentes formas para que fosse ensinado, ou seja, eles buscaram fazer a conexão entre "a compreensão pessoal para a preparação para que os outros compreendam" (SHULMAN, 2005b, p.21), configurando o conhecimento pedagógico do conteúdo. As explicações dos professores sobre sua própria prática também evidenciam suas reflexões sobre seu fazer diário, o que pode ter contribuído para que eles possam repensar suas formas de ensinar de forma a buscar uma aprendizagem cada vez mais contextualizada e significativa (ZABALA, 1998).

A observação das aulas e as análises dos professores sobre sua prática mostraram também que, no processo de transformação do seu conhecimento do conteúdo em um conhecimento ensinável, eles utilizaram estratégias de didatização semelhantes, mas com diferenças na ênfase dada a cada uma delas, indicando que a forma de trabalho de cada professor está ligada às especificidades da disciplina e à sua subjetividade. A inserção na matriz curricular no que se refere à etapa em que a disciplina é ministrada, se no início ou no final do curso, bem como as características específicas de cada conteúdo dentro da disciplina, também indicaram diferentes formas de conduzir o processo de ensino.

\begin{tabular}{l|l|l|l|l|l|l} 
(C) Rev. Educ. Perspec. & Viçosa, $M G$ & v.8 & n.2 & p.250-266 & maio/ago. 2017 & eISSN 2178-8359 \\
\hline
\end{tabular}


Constatou-se, ainda, que o perfil dos professores pesquisados, como apontado anteriormente, é marcado pela ausência de formação para o ensino, pela experiência docente de mais de catorze anos e pela vivência do cotidiano do ensino técnico como alunos na própria instituição na qual lecionam, o que possibilita algumas reflexões. Eles demonstraram em suas práticas e em seus depoimentos a preocupação com a aprendizagem dos alunos; a busca pessoal pela atualização de conhecimentos via estudos e cursos de pós-graduação, bem como a reflexão sobre a própria prática, elementos que, em conjunto, apontam para o seu compromisso manifestado pela preocupação em realizar um ensino de qualidade, viabilizando aos alunos a construção/apropriação conhecimentos teóricos e práticos necessários à sua futura profissão e à inserção no mundo do trabalho.

Esses elementos podem ter contribuído para a configuração de sua prática, ainda que tenham enfrentado, em sua trajetória profissional, desafios no desenvolvimento da atividade docente, o que indica que ausência de formação pedagógica pode ter dificultado o desenvolvimento da docência, principalmente no início da carreira. Nesse sentido, torna-se necessário valorizar os conhecimentos construídos na prática, por meio da experiência docente, mas também reafirmar a necessidade de uma compreensão mais alargada da formação docente para essa modalidade de ensino, uma formação que parta do conhecimento das práticas docentes para vinculá-las a princípios teórico-metodológicos necessários ao desenvolvimento de uma educação profissional e tecnológica de qualidade.

\section{REFERÊNCIAS}

ANDRÉ, Marli. Etnografia da prática escolar. 14. ed. Campinas, SP: Papirus, 2008.

BRASIL. Congresso Nacional. Lei $\mathbf{n}^{\mathbf{0}}$ 11.892, de 29 de dezembro de 2008. Institui a Rede Federal de Educação Profissional, Científica e Tecnológica, cria os Institutos Federais de Educação, Ciência e Tecnologia, e dá outras providências. Diário Oficial da União, Brasília, DF, 30 dez. 2008.

BOGDAN, Robert; BIKLEN, Sari. Investigação qualitativa em Educação: uma introdução à teoria e aos métodos. Tradução: Maria João Alvarez, Sara Bahia dos Santos e Telmo Mourinho Batista. Porto: Porto Editora, 1994.

CALDEIRA, Anna Maria Salgueiro; ZAIDAN, Samira. Prática pedagógica. In: OLIVEIRA, Dalila Andrade; DUARTE, Adriana Maria Cancella; VIEIRA, Lívia. Dicionário: trabalho, profissão e condição docente. Belo Horizonte: UFMG/Faculdade de Educação. CDROM.

CHEVALLARD, Yves. La transposición didáctica. Del saber sábio al saber enseñado. Tradução de Claudia Gilman. Aique Grupo Editor S. A. Buenos Aires, 1991.

\begin{tabular}{l|l|l|l|l|l|l} 
(C) Rev. Educ. Perspec. & Viçosa, $M G$ & v.8 & n.2 & p.250-266 & maio/ago. 2017 & eISSN 2178-8359 \\
\hline
\end{tabular}


FORQUIN, Jean Claude Saberes escolares, imperativos didáticos e dinâmicas sociais. Teoria e Educação, n. 5, 1992.

LIBÂNEO, José Carlos. Didática. 18. ed. São Paulo: Cortez Editora, 2001.

LOPES, Antônia Osima. Aula expositiva: superando o tradicional. In: VEIGA, Ilma Passos Alencastro (Org.) Técnicas de ensino: por que não? 12 ed. Campinas, SP: Papirus, 2001. (Coleção Magistério: formação e trabalho pedagógico).

POUPART, Jean et al. A pesquisa qualitativa: enfoques epistemológicos e metodológicos. 2. ed. Trad. Ana Cristina Nasser. Petrópolis, RJ: Vozes, 2010.

PERRENOUD, P. Práticas pedagógicas: profissão docente e formação. Perspectivas sociológicas. Lisboa: Nova Enciclopédia, 1993. 206 p.

SANTOS, Lucíola Licínio de Castro Paixão. Formação docente: questões atuais. In: I Congresso IberoBrasileiro, VI Congresso Luso-Brasileiro, IV Congresso do Fórum Português, 2010, Elvas/Cáceres/Méridas. Cadernos ANPAE. Lisboa: FPAE-PT/FEAEES/ANPAE-BR, 2010. p. 1-12. Disponível em: <http://www.anpae.org.br/iberolusobrasileiro2010/cdrom/62.pdf> Acesso em: 20 ago. 2016.

SHULMAN, Lee. El saber y entender de la profesión docente. Estudios Públicos, 99, p. 196224, Santiago, Chile, 2005a.

SHULMAN, Lee. Conocimiento y enseñanza: fundamentos de nueva reforma. In: Profesorado. Revista de curriculum y formación del profesorado. n. 9, 2. 2005b. Disponível em: 〈https://www.ugr.es/ recfpro/rev92ART1.pdf〉. Acesso em: 27 jun. 2016.

TARDIF, Michael. Saberes docentes e formação profissional. 9. ed. Petrópolis: Vozes, 2008.

TEIXEIRA, Inês Assunção de Castro. A. Da condição docente: primeiras aproximações teóricas. Educação e Sociedade, Campinas, v. 28, n. 99, p. 426-443, maio/ago, 2007.

ZABALA, Antoni. A prática educativa: como ensinar. Trad. Ernani F. da F. Rosa. Porto Alegre: Artmed, 1998.

\begin{tabular}{l|l|l|l|l|l|l} 
(C) Rev. Educ. Perspec. & Viçosa, $M G$ & v.8 & n.2 & p.250-266 & maio/ago. 2017 & eISSN 2178-8359 \\
\hline
\end{tabular}




\section{Sobre a autora}

${ }^{1}$ Geralda Aparecida de Carvalho Pena - Pedagoga e Coordenadora de Pós-graduação no Instituto Federal de Educação Ciência e Tecnologia de Minas (Campus Ouro Preto). Doutora em Educação pela Universidade Federal de Minas Gerais. E-mail: geralda.pena@ifmg.edu.br

\section{Notas}

2 Também denominadas, em outros estudos, de "disciplinas de formação específica", “disciplinas profissionalizantes" ou "disciplinas das áreas tecnológicas".

3 Trabalhos publicados originalmente em 1986 e 1987, com os títulos: Those Who understand: knowledge growth in teaching, na Educational Researcher, 1986, 15 (2), 4-14 e knowledge and teaching: Foundations of the new reform, na Harvard Educational Review, 57 (1), 1987 pp. 1-22. Estão sendo utilizadas neste trabalho as versões em espanhol desses textos, publicadas em 2005.

${ }^{4}$ São utilizados nomes fictícios para preservar a identidade dos professores.

${ }^{5}$ Conforme a matriz curricular do curso, na primeira série os alunos cursam apenas as disciplinas da área básica e Desenho técnico. Na segunda série é que ocorre maior imersão na área técnica, com cinco disciplinas.

${ }^{6}$ Refere-se à metade dos alunos da turma da $3^{\text {a }}$ série, dada a característica da aula prática. Os demais alunos dessa turma têm aulas de outra disciplina técnica no mesmo horário.

\begin{tabular}{l|l|l|l|l|l|l} 
(C) Rev. Educ. Perspec. & Viçosa, $M G$ & v.8 & n.2 & p.250-266 & maio/ago. 2017 & eISSN 2178-8359 \\
\hline
\end{tabular}

